\title{
Protein and Iron Intake Related to Growth Retardation and Anemia in Children Under 5 Years of Age, Ecuador
}

\section{Amparito del Rosario Barahona Meneses*, Jacqueline Andrea Pozo Benavidez, Gladys Edelmira Morejón Jácome, Sara Rosales Rivadeneira, Kateryn Tixilima Ayala}

Faculty of Health Sciences, Universidad Técnica del Norte, Ibarra, Ecuador

*Corresponding Author: Amparito del Rosario Barahona Meneses, Faculty of Health Sciences, Universidad Técnica del Norte, Ibarra, Ecuador

DOI: 10.31080/ASNH.2022.06.1004
Received: January 05, 2022

Published: February 09, 2022

(C) All rights are reserved by Amparito del

Rosario Barahona Meneses., et al.

\begin{abstract}
Introduction: Children under 5 years of age constitute a group vulnerable to nutritional deficiencies, with iron deficiency anemia and chronic malnutrition being the main problems that afflict children in this population. The objective was to evaluate the relationship between the consumption of protein and iron, with growth retardation, and the presence of anemia in children from 3 to 5 years of age, in a community of Cotacachi belonging to Ecuador, 2020.

Material and Methods: descriptiveor cross-sectional study and correlation. The study population consisted of 184children. Protein and iron consumption was assessed through the application of a food consumption frequency questionnaire (CFCA). Hemoglobin values were obtained from the review of medical records, and growth retardation was assessed using the height for age indicator.

Results: $21.7 \%$ of the population presented growth retardation and $29.3 \%$ was identified with iron deficiency anemia; a relationship was found between growth retardation and the consumption of theanimal proteinsource, such as meat and dairy ( $p=<0.05)$. A relationship was also found between the bgarlic consumption of foodsource of heminic iron with the presence of anemia $(p=<0.05)$.

Conclusions: Se encontró relationship between the consumption of food source of protein and iron of animal origin with the retardation of growth and iron deficiency anemia.
\end{abstract}

Keywords: Anemia; Chronic malnutrition; Protein; Iron; Ecuador

\section{Introduction}

The child population under 5 years of age constitutes one of the most vulnerable groups to nutritional deficiencies, with chronic malnutrition and iron deficiency anemia being the main public health problems in developing countries [1]. These conditions have immediate negative effects, such as the occurrence of illnessor premature deaths in children under 5 years, long-term affects school performance and work capacity [2]. The most important stage is preschool where you begin to refine your motor control, begin to slow down the rate of growth, your bones harden, there is better control and muscle rearrangement [3].
For the maintenance of organic functions, it is necessary to cover the needs of energy and nutrients through the ingestion of a healthy diet, adequate in quantity, quality, which guarantees the use of nutrients (proteins, fats, carbohydrates, vitamins and minerals), which intervene in the processes of growth and development, as well as in the repair of tissues [4].

Chronic malnutrition is a phenomenon of multifactorial origin, which is the result of social and economic [5] conditions. It begins to be established from the fourth month of age, when breast milk becomes insufficient because it is usually associated with permanent situations of insufficient intake either due to lack of access to 
food, lack of health care, the use of unhealthy water and sanitation systems and poor care and feeding practices as occurs in households with poverty, causing physical damage, irreversible impairment of cognitive ability and motor delays [6].

Another important issue that significantly afflicts the state of health of children and that also influences their growth and development, is the presence of iron deficiency anemia, due to inadequate nutrition and frequent blood losses. At certain times in life there is an increase in iron requirements, such as in the gestation stage, in periods of accelerated growth such as in childhood and adolescence, therefore an inadequate supply of iron has as Important alterations in cognitive development can also cause hypomyealization and affect the synthesis of neurotransmitters, decreasing concentration, speed and accuracy in auditory, visual, spatial and immediate memory tests [7].

In the annual report of the UN it is reflected that some 155 million children under 5 years of age suffer from stunting that is (height too short for their age) [8], In Ecuador in the latest $\mathrm{Na-}$ tional Health and Nutrition Survey (ENSANUT- ECU2012), 25.3\% of the population with chronic malnutrition corresponds to children under 5 years [9], regarding anemia, the WHO mentions that $24.8 \%$ of people worldwide have it, of these $47.4 \%$ are preschool children [10]. According to the ENSANUT 2012 in Ecuador 25.7\% of children of preschool age suffer some degree of anemia; in the face of these high figures the Ministry of Public Health (MSP) considered establishing protocols and counseling for supplementation with micronutrients, despite this there are still high percentages of anemia in children, as indicated by the United Nations Children's Fund (UNICEF 2017), indicating that 70\% among children under one year old suffer from anemia, andespecially those who live in rural areas of the mountains where the figures reach up to $84 \%$, therefore these figures show that Ecuador is one of the most affected countries in this situation compared to other Latin American countries [11]. Therefore, the objective of this study was to explore the intake of protein and iron, and its relationship with growth retardation, and the presence of iron deficiency anemia, in children aged 3 to 5 years, from the Cotacachi canton, Ecuador.

\section{Material and Methods}

The present study was descriptive, cross-sectional and correlation. It was developed under ethical principles of research Biomedica, sand obtained institutional permission for the collection of information by the director of the center of savalanche off canton Cotacachi. The children's mothers signed the respective informed consent to participate in the study.

Population and sample

The present research was carried out in the "NestedHealthCenter" of the Cotacachi canton, belonging to the province of Imbabura in Ecuador, the collection of the data was carried out during the months of January to March 2020. The study population consisted of 184 children between 3 and 5 years of age, who attended control during this period. She applied the food consumption frequency questionnaire (CFCA) only those children who presented some degree of anemia and growth retardation.

For the collection of the data, techniques were used such as, review of the clinical histories of the children, from which the hemoglobin values were obtained, which was taken with an $\mathrm{Hb} 201$ Hemo Cue analyzer, considering the following cut-off points: normal hemoglobin $>12 \mathrm{~g} / \mathrm{dl}$, mild anemia $11.0-11.9 \mathrm{~g} / \mathrm{dl}$, to moderate nemia: $8.0-10.9 \mathrm{~g} / \mathrm{dl}$, and to severenemia: $<8.0 \mathrm{~g} / \mathrm{dl}$, adjusted for altitude.

To assess the growth according to the age size indicator, we proceeded to take the size in a portable SECA 213 tallimeter with precision of $1 \mathrm{~mm}$, alcance of 20 to $250 \mathrm{~cm}$, the general protocols established for the anthropometric technique were complied with. To categorize this indicator, the growth patterns established by the WHO were used as a reference, which considers the following cutoff points: between +2 and -1 standard deviations (SD) as adequate or normal size for age, between -1 and -2 SD risk of low height, and below -2 SD growth retardation or chronic malnutrition. For the calculation of $\mathrm{Z}$ scores and growth curves at the global level and by sex, the WHO Anthro V 3.2.2 program was used for the WHO standards (2006) [12].

Sociodemographic data such as: sex, age, ethnicity of children; the level of education, marital status, occupation of fathers and housing conditions were obtained through the application of a structured survey aimed at mothers.

To assess food intake, a food consumption frequency questionnaire (CFCA) was applied, adapted only with foods sources 
Protein and Iron Intake Related to Growth Retardation and Anemia in Children Under 5 Years of Age, Ecuador

of protein and iron available in that locality, in order to define the relationship between growth retardation and anemia with the consumption of foods sources of these nutrients. Cfca results were stratified according to the number of times a food was mentioned: daily consumption, average consumption ( 3 to 4 times a week), low intake ( 1 to 2 times a week), occasional consumption ( 1 to 3 times a month), and no consumption.

Statistical analysis was performed in the SPSS version 25.0 program. Tables of frequency distributions (absolute and percentage) were elaborated. To analyze the level of relationship between growth retardation and anemia with the consumption of foods source of protein and iron, Pearson's Chi square test was used, in- dicating that there is a relationship in the crossing of variables with an assessment of $\mathrm{p}<0.05$.

\section{Results}

Table 1 shows the sociodemographic characteristics of children and their mothers as well as their living and access to basic services, in which $70.7 \%$ of children are of mestizo ethnicity, $56.5 \%$ are female and 58.2\%are between 4 and 5 years old. Most are children of married fathers (57.1\%), mothers are engaged in domestic chores $(61 \%)$ and $47.3 \%$ of mothers finished primary school and most families (68.5\%) are made up of 4 to 5 members. $59.8 \%$ of families had households. A large percentage of this population has access to basic services such as drinking water (96.7\%), and sewerage $(97.8 \%)$.

\begin{tabular}{|c|c|c|c|c|c|c|c|c|c|}
\hline \multicolumn{10}{|c|}{ Sociodemographic characteristics of children } \\
\hline Age (years) & No & $\%$ & \multicolumn{4}{|c|}{ Sex No\% Ethnicity } & \multicolumn{2}{|c|}{ No } & $\%$ \\
\hline 3 a 4 & 77 & 41.8 & Female & 104 & 56.5 & Mestizo & \multicolumn{2}{|c|}{130} & 70.7 \\
\hline 4 a 5 & 107 & 58.2 & Male & 80 & 43.5 & Indigenous & \multicolumn{2}{|c|}{53} & 28.8 \\
\hline & & & & & & Black & \multicolumn{2}{|l|}{1} & 0.5 \\
\hline \multicolumn{10}{|c|}{ Sociodemographic characteristics of mothers } \\
\hline \multicolumn{2}{|l|}{ Marital status } & No & $\%$ & \multicolumn{3}{|c|}{ Level of instruction } & \multicolumn{2}{|c|}{ No } & $\%$ \\
\hline \multicolumn{2}{|l|}{ Bachelor } & 24 & 13 & \multicolumn{3}{|c|}{ Primary } & \multicolumn{2}{|c|}{87} & 47.3 \\
\hline \multicolumn{2}{|l|}{ Married } & 105 & 57.1 & \multicolumn{3}{|c|}{ Incomplete secondary } & \multicolumn{2}{|c|}{79} & 42.9 \\
\hline \multicolumn{2}{|l|}{ Common-law marriage } & 55 & 29.9 & \multicolumn{3}{|c|}{ Complete Secondary } & \multicolumn{2}{|c|}{18} & 9.8 \\
\hline \multicolumn{10}{|c|}{$\mathrm{n}=184$} \\
\hline \multicolumn{2}{|l|}{ Occupation } & No & $\%$ & \multicolumn{3}{|c|}{ Number of family members } & \multicolumn{2}{|c|}{ No } & $\%$ \\
\hline \multicolumn{2}{|l|}{ Merchant } & 36 & 19.6 & \multicolumn{3}{|c|}{1 to 3 members } & \multicolumn{2}{|c|}{30} & 16.3 \\
\hline \multicolumn{2}{|l|}{ artisan } & 36 & 19.6 & \multicolumn{3}{|c|}{4 to 5 members } & \multicolumn{2}{|c|}{126} & 68.5 \\
\hline \multicolumn{2}{|l|}{ Housework } & 112 & 60.9 & \multicolumn{3}{|c|}{ More than 6 members } & \multicolumn{2}{|c|}{28} & 15.2 \\
\hline \multicolumn{10}{|l|}{$\mathrm{n}=184$} \\
\hline \multicolumn{10}{|c|}{ Housing tenure and basic services } \\
\hline Tenure of vivienda & No & $\%$ & Water supply & No & $\%$ & Wastewate & & No & $\%$ \\
\hline lease & 64 & 34.8 & Drinking water & 178 & 96.7 & sewer s & & 180 & 97.8 \\
\hline Own & 110 & 59.8 & Cistern & 6 & 3.3 & Pozo & & 4 & 2.2 \\
\hline Lent & 10 & 5.4 & & & & & & & \\
\hline
\end{tabular}

Table 1: Sociodemographic characteristics of children from 3 to 5 years old. Cotacachi, Ecuador $\mathrm{n}=184$. 
Table 2 shows the data on growth in relation to age, and the presence of anemia in children aged 3 to 5 years in this sector, in which $22 \%$ of these children have low height (<-2DE), that is, 2 out of 10 children have chronic malnutrition according to the height/ age indicator. In addition, a large percentage of this population has a risk of short stature (between -1 and -2 SD) exceeding those of normal size. When assessing hemoglobin ( $\mathrm{Hb}$ ) levels, it was found that $29.4 \%$ of this population presented some level of anemia between mild and moderate. That is to say that 3 out of 10 children in this population, who attended the Nested Health Center in the period from January to March 2019, presented iron deficiency anemia (Table 2).

It should be noted that the children in this study come from lowincome households, which despite the diversity in local production, do not have access to a balanced and varied diet, which together with the low education of their parents, further complicates this serious nutritional problem in vulnerable groups such as preschoolers.

\begin{tabular}{|l|c|c|c|c|c|}
\hline Size/age & No & $\mathbf{\%}$ & Anemia levels & No & $\mathbf{\%}$ \\
\hline Normal & 68 & 37 & Mild anemia & 36 & 19.6 \\
\hline Risk of low size & 76 & 41 & Moderate anemia & 18 & 9.8 \\
\hline Low size & 33 & 18 & No anemia & 130 & 70.6 \\
\hline $\begin{array}{l}\text { Severe short } \\
\text { stature }\end{array}$ & 7 & 4.0 & & & \\
\hline
\end{tabular}

Table 2: Size for age andanaemia levels in children aged 3 to 5 years in the canton of Cotacachi. Ecuador $\mathrm{n}=184$.

\begin{tabular}{|c|c|c|c|c|c|}
\hline \multicolumn{6}{|c|}{ Frequency of consumption of protein-source foods in children with short stature } \\
\hline Food & Daily consumption & $\begin{array}{c}\text { Average consumption } \\
\text { (3-4 times/week) }\end{array}$ & $\begin{array}{l}\text { Low consumption } \\
(1-2 \text { times/week) }\end{array}$ & $\begin{array}{c}\text { Occasional consumption } \\
\text { (1-3 times/month) }\end{array}$ & $\begin{array}{l}\text { Does not } \\
\text { consume }\end{array}$ \\
\hline Meats & & 8.7 & 51.6 & 39.7 & \\
\hline Dairy & 2.2 & 27.2 & 41.8 & 17.4 & 11.4 \\
\hline Eggs & 27.0 & 22.2 & 48.1 & & 2.7 \\
\hline Seafood & & & & 17.5 & 82.5 \\
\hline Fish & & & 14.2 & 82.8 & 3.0 \\
\hline Viscera & & 8.2 & 55.4 & 29.3 & 7.1 \\
\hline Liver & & & & 77.7 & 22.3 \\
\hline \multicolumn{6}{|c|}{ Frequency of consumption of iron-source foods in children with anemia } \\
\hline Food & Daily consumption & $\begin{array}{c}\text { Average consumption } \\
\text { (3 - } 4 \text { times/week) }\end{array}$ & $\begin{array}{l}\text { Low consumption } \\
\text { (1 - } 2 \text { times/week) }\end{array}$ & $\begin{array}{c}\text { Occasional consumption } \\
\text { (1 - } 3 \text { times/month) }\end{array}$ & $\begin{array}{l}\text { Does not } \\
\text { consume }\end{array}$ \\
\hline Spinach & & 3.8 & 35.3 & 60.9 & \\
\hline Watercress & & & 20.7 & 79.3 & \\
\hline Broccoli & & 2.7 & 44.6 & 52.7 & \\
\hline Chard & & & 47.3 & 52.7 & \\
\hline With green & & & 29.3 & 70.7 & \\
\hline Neighbour & & 13.6 & 54.9 & 16.3 & 15.2 \\
\hline liver & & & & & \\
\hline
\end{tabular}

Table 3: Frequency of consumption of foods that are sources of protein and iron in children with short stature and anemia.

As shown in Table3, in terms of the consumption of protein from animal sources, there is a low intake ( 1 to 2 times a week) and an occasional consumption (1 to 3 times a month) of foods that are the source of this nutrient such as meats, dairy products and eggs, which should be part of the daily diet of children to contribute to their growth; only $27 \%$ of children consume eggs. Every day.
Similarly, in this area, despite the availability of vegetables sources of iron such as: spinach, watercress, broccoli, chard, green cabbage and turnip, a low consumption (1 to 2 times/week) and occasional (1 to 3 times/month) of these foods is observed. Likewise, liments with a high concentration of iron such as beef liver and chicken, consume it on a monthly basis and others do not consume it. 


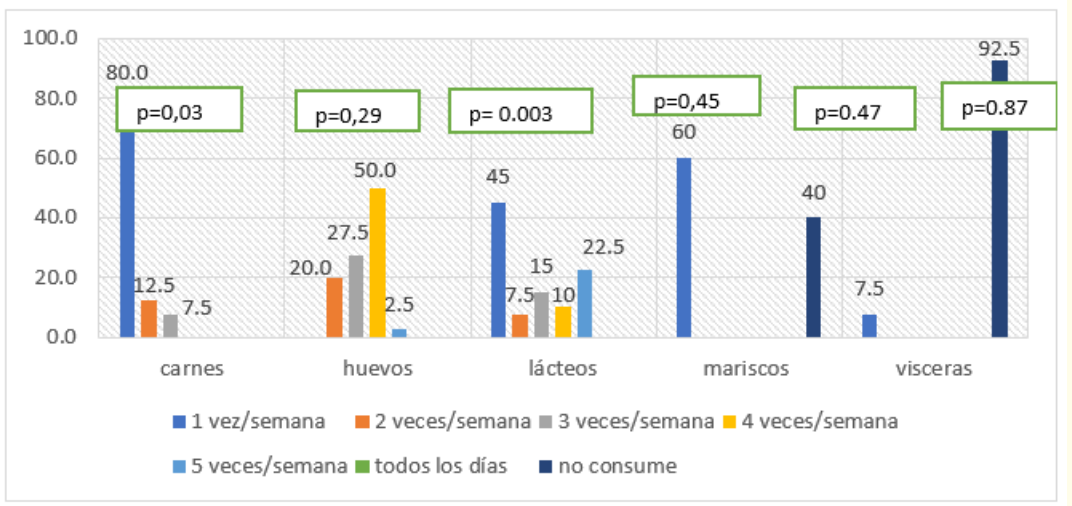

Figure 1: Growth retardation related to the consumption of protein-source foods in children from 3 to 5 years of age in the Cotacachi canton. Ecuador.

Nutritionally, proteins are considered an indispensable nutrient for life and health, its plastic and structural function makes it an essential nutrient in the diet of children, where the requirements are higher than those of adults $(1.5 \mathrm{~g} / \mathrm{kg} /$ day in children from 3 to 5 years) [13]. So an insufficient consumption of quality proteins that provide all the essential amino acids, such as those of animal origin ends up reflecting in children a low pondostatatural development. In this study according to Figure 1, a direct relationship of the low size of children with the consumption of protein sources of high biological value such as meats $(p=0.03)$ and dairy $(p=0.003)$ was observed.
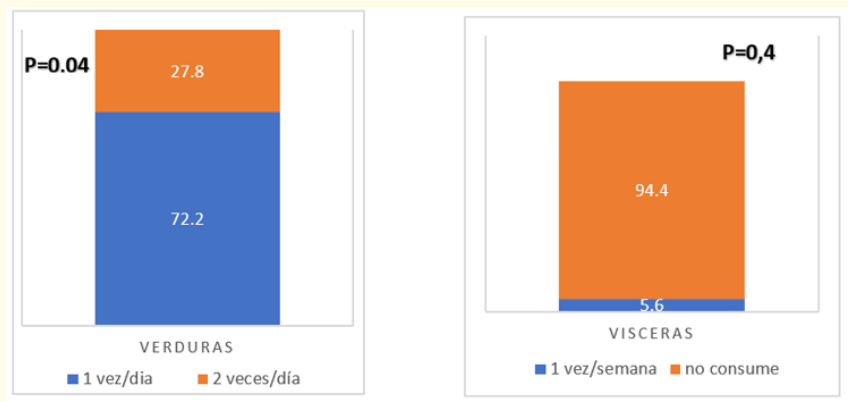

Figure 2: Presence of anemia related to the consumption of iron source foods in children from 3 to 5 years of age in the Cotacachi canton. Ecuador.
For the maintenance of organic functions, growth and development it is necessary to consume the food in adequate quantities, otherwise nutritional problems such as anemia and malnutrition occur. Nutritional iron deficiency occurs when iron requirements cannot be met through the diet, especially in populations whose usual diets are scarce in meat products [14]. Some studies argue that even in the presence of mild iron deficiency, the cognitive function and emotional and behavioral development of preschool and school children is impaired, as is immune system function and physical ability in all age groups [15].

In this study according to Figure 2, a relationship is observed in terms of the presence of anemia with the consumption of iron foods, especially vegetables $(p=0.04)$.

\section{Discussion}

The ENSANUT-ECU 2012 survey identified a 26\% prevalence of height delay in Ecuadorian children aged 24 to 60 months, with $30.7 \%$ in the Imbabura area, and $25.7 \%$ of iron deficiency anemia nationwide. In our study, the prevalence of short stature was $22 \%$ and $29.4 \%$ for anemia, finding a statistical association between these states with the consumption of foods source of protein and iron $(\mathrm{p}<0.05)$.

A study carried out in children of the EquiDar project in the region of Azuay Cuenca in 2016, found a prevalence of anemia of 
23.9\%with predominance in the preschool ager and in rural area of residence, a health problem that attribute it to sociodemographic variables that exceed the nutritional dimension [16].

In Peru, the2013 Demographic and Family Health Survey found a prevalence of anemia of $43.5 \%$ in children under 5 years of age, residents of rural areas and of a low economic level, which would limit access to a healthy and varied diet [17]. In our analysis, the prevalence of anemia was lower (25.7\%), being noticeable and distant the difference, which is perhaps due to the fact that the families in our study have basic services such as water and sewerage, necessary to maintain hygiene and minimum health conditions against parasitosis. However, in both investigations the presence of anemia is explained to a deficient consumption of food sources of ferric iron.

The high prevalence of anemia in our study was 3.6 percentage points higher than that found nationwide $(25.7 \%)$. This shows that disparities between rural and urban areas remain noticeable throughout the country and reinforce a reality in which the rural child population has one of the highest prevalence's of anaemia and chronic malnutrition in the country.

Iron deficiency is considered the most frequent cause of anemia in the world, due to this situation, the Ministry of Public Health (MSP) has implemented nutritional counseling protocols and supplementation with iron and zincin children under 5 years of age. Pero there are still cases of anemia in Ecuador, so it should be considered to provide adequate and sufficient food to meet the nutritional needs of this vulnerable group.

In Ecuador, chronic malnutrition (DC) or short stature for age (25.2\%) continues to be a major public health problem in children from 0 to 60 months. Between 2006 and 2014, according to the Survey of Living Conditions of Ecuador, chronic malnutrition fell by just one and a half points, from $25.8 \%$ to $24.1 \%$ despite millionaire investments in social development programs [18]. In our study, 2 out of 10 children have chronic malnutrition related to a deficient intake of protein sources of animal origin such as meat and dairy products, known for their high biological value or higher quality, since they contain all the amino acids that the body cannot produce and that are essential during the growth process, in addition to other vital functions such as the formation of ferritin which is the main iron storage protein. The presence of DC creates the necessary conditions for anemia, or both, if a child is malnourished for a long time with a low consumption of protein from animal sources, it will hinder the production of erythropoietub consequently the production of red blood cells, thus causing anemia.

A study conducted in Bolivia in 2014, which evaluated the prevalence of chronic malnutrition in children under 5 years of age treated at the Tacopaya Health Center [19], found a prevalence of $16 \%$, a figure lower than those found in our study (21.7\%). DC in Bolivia, as in Ecuador is a very serious problem that mainly affects the rural population, and therefore, an indicator of the effectiveness and concurrence of services and actions of states, society and families, it reflects the productivity of its population and its capacities for socioeconomic development.

The results obtained in this research show the need for an intervention in the improvement of health services, emphasizing nutritional education that promotes the consumption of a varied and sufficient diet with locally produced foods, which covers the needs and nutritional requirements of the most vulnerable population and who live in situa Insecurity and exclusion, and thus contribute to closing gaps in health and nutrition that still persist in the country.

\section{Gratitude}

Special thanks to the Anidad health center in Cotacachi.

\section{Bibliography}

1. World Health Organization. (WHO). "Electronic library of scientific documentation on nutritional measures". Life cycle (2013).

2. Alcázar L., et al. "Economic impact of chronic, acute and global malnutrition in Peru". Revista Peruana de Medicina Experimental Public Health 30.4 (2013): 569-574.

3. Soto R., et al. "Preschool Nutrition" (2016).

4. Ministry of Health, WHO, PAHO, INCAP. "Methodological Guide for the Teaching of Food and Nutrition" (2013).

5. Sánchez J. "Evolution of chronic malnutrition in children under 5 years of age in Peru". Revista Peruana de Medicina Experimental Public Health 9.3 (2012): 402-405.

6. Sobrino M., et al. "Child malnutrition in children under five years of age in Peru: trends and determining factors". Pan American Journal of Public Health. Lima Peru 35.2 (2014): 104-112. 
7. García Y., et al. "Neural development and iron deficiency". Revista CENIC Ciencias Biológicas 36 (2005).

8. World Health Organization (WHO). "World hunger is growing again, driven by conflict and climate change, according to a new UN report" (2017).

9. Freire W., et al. "National Health and Nutrition Survey". (ENSANUT-ECU,2012). Nutritional Status based on anthropometric indicators 1 (2012): 215.

10. World Health Organization (WHO). "World Guide Prevalence of Anemia. Geneva" 2005

11. United Nations Children's Fund". UNICEF (2016).

12. WHO Anthro for Personal Computers, version 3. "Software to assess the growth and development of the world's children". Geneva: WHO (2009).

13. FAO, Module 2. Nutritional Needs.

14. Zimmermann M and Hurrell R. "Nutritional iron deficiency". The Lancet 370.9586 (2007): 511-520.

15. WHO. "Iron Deficiency Anaemia Assessment, Prevention, and Control. A guide for programme managers". World Health Organization (2001).

16. Román C., et al. "Prevalence of anemia in children of the EquiDar project of the region of Azuay-Ecuador". Revista Cubana de Pediatría 90.4 (2018).

17. Flores J., et al. "Chronic malnutrition and anemia in children under 5 years of age from indigenous households in Peru". Analysis of the Demographic and Family Health Survey. Universidad Nacional Mayor de San Marcos, Faculty of Medicine. Lima, Peru (2013).

18. Plan V Multimedia Magazine. "Chronic malnutrition, a story of a failure made up".

19. Lafuente Y., et al. "Prevalence of chronic malnutrition in children under 5 years of age treated at the Tacopaya Health Center, first semester management" . Bolivian Medical Gazette 39.1 (2014).

\section{Assets from publication with us}

- Prompt Acknowledgement after receiving the article

- Thorough Double blinded peer review

- Rapid Publication

- Issue of Publication Certificate

- High visibility of your Published work

Website: www.actascientific.com/

Submit Article: www.actascientific.com/submission.php

Email us: editor@actascientific.com

Contact us: +919182824667 